\title{
The Relationship between Students' Conceptions of Learning and Their Academic Achievement
}

\author{
Ghorban Hemati Alamdarloo ${ }^{1}$, Shahram Moradi $^{2}$, Gholam Reza Dehshiri ${ }^{3}$ \\ ${ }^{1}$ Faculty of Psychology and Education, Shiraz University, Shiraz, Iran \\ ${ }^{2}$ Department of Behavioral Sciences and Learning, Linköping University, Linköping, Sweden \\ ${ }^{3}$ Faculty of Psychology and Education, Alzahra University, Tehran, Iran \\ Email: shahram.moradi@liu.se
}

Received October $7^{\text {th }}, 2012$; revised November $5^{\text {th }}, 2012$; accepted December $2^{\text {nd }}, 2012$

\begin{abstract}
This study investigates the relationship between pre-university students' conceptions of learning with their academic achievement. The sample consisted of 309 students (165 males and 144 females) in Tehran city. Among them, 104 individuals were in Mathematics, 110 in Experimental Science, and 95 in Literature (Humanities). The participants were selected through multistage cluster sampling. To assess their conceptions of learning, Purdie and Hattie's (2002) questionnaire was used, and to measure their academic achievement, the total mean of high school diploma was considered. The results showed a significant relationship between students' conceptions of learning and their academic achievement. There is also a meaningful relationship between students' number of conceptions of learning and their academic achievement.
\end{abstract}

Keywords: Conceptions of Learning; Academic Achievement; Pre-University Student

\section{Introduction}

Learning is a complex process that is not easily defined. Perhaps the most famous definition of learning is as follows: Learning is almost as table changing process in behavior or behavioral power that is the result of experience, and it is not attributed to a temporary state of one's body like what is created as the effect of disease, tiredness, or drug use (Seif, 2008). This definition does not consider the various cognitive processes used in learning or personal, social, and emotional aspects of it (Entwistle \& Peterson, 2004). For example, Klatter, Lodewijks, and Aarnouste's (2001) opinion poll indicated that people have different ideas about learning, in which some point to learning consequences, some to learning necessities, and others to learning purposes.

These various and adjoining dimensions of learning lead to the idea that learning is a multidimensional construct (Peterson, Brown, \& Irving, 2010). This characteristic of multidimensionality allows students to hold differentconceptions of learning (Dart et al., 2000). Conceptions of learning are defined as a learner's ideas and beliefs about learning (Lai \& Chan, 2005). Since conceptions of learning are formed by the learner's cultural values (Hong \& Salili, 2000), six basic conceptions of learning are recognized across different cultures and societies such as the United States, Australia, Malaysia (Purdie \& Hattie, 2002), China (Lai \& Chan, 2005), and New Zealand (Peterson et al., 2010). They are such as follows: learning as gaining information, learning as remembering and using information, learning as a duty, learning as personal change, learning as a process not bound by time or place, and learning as the development of social competence.

The researchers divided conceptions of learning on a hierarchical continuum as surface or quantitative versus deep or qualitative learning conceptions (Boulton-Lewis, Marton, Lewis,
\& Wilss, 2000). Quantitative conceptions of learning include the gaining and restructuring of information, whereas qualitative conceptions contain the understanding of meaning and personal change (Purdie \& Hattie, 2002). Marton, Dall'Alba, and Beaty (1993) proposed that the six conceptions of learning are hierarchical; the first three conceptions emphasize learning quantitative material, and the last three focus on qualitative material as well as the role of meaning in learning. Learning as gaining information is at the lowest level in the conceptions of learning hierarchy, whereas learning as an individual's personal change and development is at the highest level (Lai \& Chan, 2005).

Purdie and Hattie (2002) believed that when students' conceptions of learning are high in the hierarchy, they have better learning and greater academic achievement. To support this theory, Watkins (1984, cited in Allan, 2003) and Watkins and Stilla (1982, cited in Allan, 2003) revealed that a relationship exists between the depth of students' conceptions of learning and their academic achievement, such that the deeper the students' conceptions of learning are, the higher these conceptions are in the hierarchy and the better their academic achievement.

Additionally, Mclean (2001) declared that there is a relationship between students' conceptions of learning and academic achievement. In this regard, Allan (2003) concluded that students' conceptions of learning can thoroughly predict their academic achievement. Moreover, Boulton-Lewis et al.'s (2000) finding showed that there is a strong relationship between students' conceptions of learning and their learning results.

Congruent with these research findings, Entwistle and Peterson (2004) found that there is a significant relationship between deep learning with high academic function and surface learning with weak academic function. Overall, these studies reveal that students' conceptions of learning affect their learning motivetion, the cognitive strategies they select, and their academic achievement (Hong \& Salili, 2000; Purdie et al., 1996). 
To support their theories, Purdie and Hattie (2002) claimed that there is a relationship between the number of students' conceptions of learning and their academic achievement, such that the greater the numbers of students' conceptions of learning, the better their academic achievement.

Purdie and Hattie (2002) showed that the mean scores of students who have six conceptions of learning are considerably higher than the scores of those who do not have any. Therefore, according to conceptions of learning theory, there is a relationship between the number and level of students' conceptions of learning and their academic achievement. Previous studies have analyzed conceptions of learning in various countries, but no direct research on this topic has been carried out in Iran. Understanding conceptions of learning in Iran is an important topic, as cultural differences influence students' conceptions of learning (Purdie \& Hatti, 2002), and Iran differs culturally from the other countries where conceptions of learning have been studied. In addition, the methods used to assess student learning in Iran are different as well. In Iran, assessment methods are based on quantity methods and scores $(0-20)$, where a higher score indicates better academic achievement. Thus, the study of the relationship between Iranian students' conceptions of learning and their academic achievement offers cultural insights that have not yet been achieved by previous studies. This research seeks to answer the following questions.

Is there any relationship between conceptions of learning and academic achievement for pre-university students in Iran?

Which conceptions of learning play a significant role in predicting the academic achievement of pre-university students?

\section{Method}

The research method was descriptive, and the statistical population consisted of all the pre-university students who were studying in Tehran in 2006-2007. A sample of 309 students (165 boys and 144 girls) was selected through multistage cluster sampling. Among them, there were 104 students in Mathematics, 110 in Experimental Science, and 95 in Literature (Humanities). For the sampling, two districts (Districts 7 and 11) were selected among the 19 areas of Tehran. Then, a list of pre-university centers in selected areas was prepared, and one center was randomly selected from each area of girl and boy pre-university centers ( 4 centers total). Then, through reference to the selected centers and coordination with school administrators, students who wanted to participate in the study were selected. The selection process took into account the participants' satisfaction and willingness to volunteer. In addition, the participants were made aware of the purpose of the research and the study process. They were assured that all their information would remain confidential. The participants were $16-20$ years old with a mean age of 17.39 and standard deviation of .78 .

\section{Measurement Instruments}

\section{Conceptions of Learning Questionnaire}

The Conceptions of Learning Questionnaire by Purdie and Hattie (2002) consists of 32 items and 6 subscales as follows: learning as gaining information ( 5 items), learning as remembering and using information ( 9 items), learning as a duty (3 items), learning as a personal change ( 8 items), learning as a process not bound by time or place ( 3 items), and learning as the development of social competence (4 items). The items were rated on a 6-point Likert scale from 1 "agree" to 6 "disagree." The participants were requested to assess their success on the scale. The scores of subscales were calculated with the total scores of questions in the related subscales. The results of confirmative factorial analysis revealed that the 6-factorial structure of the questionnaire was suitable for the students (Purdie \& Hattie, 2002).

\section{Academic Achievement}

In this study, participants' total mean of high school diploma was used as an indicator of academic achievement. The total mean of high school diploma consists of students' scores in special lessons determined by Iran's Ministry of Education. These lessons are different in each field of study as follows: Mathematics (Arithmetic, Geometry 2, Algebra, Chemistry 3, Physics 3, Religion and Life, Literature, and English and Arabic Language); Experimental Science (Biology 3, Chemistry, Mathematics, Religion and Life, Literature, English and Arabic Language, and Statistics); and Literature (Religion and Life, Literature, English and Arabic Language, and Contemporary History). These exams are given throughout the country in the last year of high school. They are administered by the Ministry of Education and are a standard criterion for assessing academic achievement.

\section{Results}

Table 1 shows means of variables used in this study. As seen in the Table 2, the correlations of all conceptions of learning with academic achievement are significant. The weakest correlation is related to the conception of learning as a duty ( $\mathrm{r}=$ $0 / 28$ ), and the strongest to the conception of learning as personal change $(r=0 / 36)$.

Table 3 shows the results of step-by-step regression analysis in order to investigate which conceptions of learning have a significant role in predicting academic achievement. As observed in the first step, the conception of learning as the development of social competencies explains $15 \%$ of the variance in academic achievement $\left[\mathrm{F}(1,307)=53.65, p<.001, \mathrm{R}^{2}=.15\right]$.

In the second step, the conceptionof learning as a process not bound by time or place was entered into the equation in which thecoefficient of determination increased to $17 \%[\mathrm{~F}(2,306)=$ $\left.30.94, p<.001, \mathrm{R}^{2}=.17\right]$. Other variables were not entered in the equation because they do not play a significant role in predicting academic achievement.

To investigate whether the numbers of conceptions of learning and academic achievement are related or not, first, participants were divided into two groups, those with conceptions of learning and those without, based on the mean of each conception of learning. Then, the numbers of conceptions of learning were calculated from 0 to 6 . Table 4 shows the mean and standard deviation of academic achievement on the basis of the number of conceptions of learning. Participants' academic achievement mean on the basis of the number of their conceptions of learning were compared using ANOVA.

As seen in the Table 5, there is a significant difference among academic achievement means on the basis of the number of conceptions of learning $[\mathrm{F}(6,302)=11.76, p<.0001)]$.

To assess which two groups differed significantly, a Scheffe test was used to compare academic achievement on the basis of the number of conceptions of learning. The results are shown in Table 6. As seen in the table, the mean of academic 
Table 1.

Means and standard deviations (SD) of the research variables.

\begin{tabular}{ccccc}
\hline Variable & Mean & SD & Minimum & Maximum \\
\hline Academic achievement & 16.51 & 2.02 & 10.12 & 19.96 \\
Learning as gaining information & 20.42 & 5.31 & 5 & 30 \\
Learning as remembering and using information & 38.29 & 10.55 & 10 & 54 \\
Learning as a duty & 12.30 & 3.23 & 3 & 18 \\
Learning as personal change & 33.78 & 9.73 & 3 & 48 \\
Learning as a process not bound by time or place & 12.28 & 2.99 & 4.24 & 18 \\
Learning as the development of social competence & 16.53 & 4.5 & 24 \\
\hline
\end{tabular}

Table 2.

Matrix of conceptions of learning and academic achievement.

\begin{tabular}{|c|c|c|c|c|c|c|}
\hline Variable & 1 & 2 & 3 & 4 & 5 & 6 \\
\hline 1-Academic achievement & 1 & & & & & \\
\hline 2-Learning as gaining information & $0 / 33^{*}$ & 1 & & & & \\
\hline 3-Learning as remembering information & $0 / 34^{*}$ & $0 / 82^{*}$ & 1 & & & \\
\hline 4 - Learning as a duty & $0 / 28^{*}$ & $0 / 66^{*}$ & $0 / 66^{*}$ & 1 & & \\
\hline 5-Learning as personal change & $0 / 36^{*}$ & $0 / 79^{*}$ & $0 / 82^{*}$ & $0 / 69^{*}$ & 1 & \\
\hline 6 - Learning as a process not bound by time or place & $0 / 33^{*}$ & $0 / 71^{*}$ & $0 / 66^{*}$ & $0 / 59^{*}$ & $0 / 78^{*}$ & 1 \\
\hline 7-Learning as the development of social competence & $0 / 37^{*}$ & $0 / 68^{*}$ & $0 / 66^{*}$ & $0 / 66^{*}$ & $0 / 76^{*}$ & $0 / 72^{*}$ \\
\hline
\end{tabular}

${ }^{*} p<.01$.

Table 3.

Results of step-by-step regression of academic achievement based on conceptions of learning.

\begin{tabular}{ccccccc}
\hline Step & $\begin{array}{c}\text { Predictive } \\
\text { variable }\end{array}$ & $\mathrm{B}$ & $\mathrm{SEB}$ & $\beta$ & $\mathrm{R}$ & $\mathrm{R}^{2}$ \\
\hline Step 1 & $\begin{array}{c}\text { Learning as a } \\
\text { development of } \\
\text { social competence } \\
\text { Learning as a } \\
\text { development of } \\
\text { social competence } \\
\text { Learning as a } \\
\text { process not bound } \\
\text { by time or place }\end{array}$ & $0 / 18$ & $0 / 02$ & $0 / 39^{*}$ & $0 / 39$ & $0 / 15^{*}$ \\
Step 2 & $0 / 11$ & $0 / 04$ & $0 / 23^{*}$ & $0 / 41$ & $0 / 17^{*}$ \\
\hline${ }^{*} p<.01$. & & $0 / 05$ & & & \\
\hline
\end{tabular}

Table 4.

Mean and standard deviation of academic achievement on the basis of number of conceptions of learning.

\begin{tabular}{cccc}
\hline Number of conceptions of learning & Mean & SD & Numbers \\
\hline 0 & 15.28 & 2.12 & 51 \\
1 & 15.96 & 2.24 & 19 \\
2 & 15.89 & 1.98 & 14 \\
3 & 16.14 & 1.79 & 1.89 \\
4 & 16.08 & 1.64 & 30 \\
5 & 16.92 & 1.83 & 50 \\
6 & 17.54 & & 119 \\
\hline
\end{tabular}


Table 5.

Results of ANOVA.

\begin{tabular}{ccccc}
\hline Changing resources & Sum of squares & Freedom degree & Sum of squares mean & F \\
\hline Intergroups & 232.89 & 6 & 38.69 & 11.76 \\
Intragroups & 993.89 & 302 & 3.29 & .0001 \\
Total & 1226.08 & 308 & - & \\
\hline
\end{tabular}

Table 6.

Results of a Scheffe test to compare academic achievement on the basis of the number of conceptions of learning.

\begin{tabular}{|c|c|c|c|}
\hline Group & Compared group & Mean difference & Sig. \\
\hline \multirow{6}{*}{0} & 1 & -.68 & .92 \\
\hline & 2 & -.61 & .93 \\
\hline & 3 & -.86 & .87 \\
\hline & 4 & -.79 & .73 \\
\hline & 5 & -1.64 & .003 \\
\hline & 6 & -2.26 & .001 \\
\hline \multirow{5}{*}{1} & 2 & -.07 & .99 \\
\hline & 3 & -.17 & .99 \\
\hline & 4 & -.10 & .99 \\
\hline & 5 & -.95 & .70 \\
\hline & 6 & -1.58 & .05 \\
\hline \multirow{4}{*}{2} & 3 & -.24 & .99 \\
\hline & 4 & -.18 & .99 \\
\hline & 5 & -1.03 & .48 \\
\hline & 6 & -1.65 & .008 \\
\hline \multirow{3}{*}{3} & 4 & -.07 & .99 \\
\hline & 5 & -.78 & .91 \\
\hline & 6 & -1.40 & .27 \\
\hline \multirow{2}{*}{4} & 5 & -.85 & .66 \\
\hline & 6 & -1.47 & .22 \\
\hline 5 & 6 & -.62 & .66 \\
\hline
\end{tabular}

achievement among participants who had no conceptions of learning is significantly less than those who had five or six conceptions of learning. Additionally, the mean of academic achievement among participants with one or two conceptions of learning is significantly less than the mean of those with six conceptions of learning.

\section{Discussion and Conclusion}

The purpose of this research was to study the relationship between students' conceptions of learning and their academic achievement. The findings showed there is significant relationship among all the conceptions of learning and academic achievement. Among different conceptions of learning, learning as a process not bound by time or place and learning as the development of social competence have a significant role in predicting academic achievement. This finding is congruent with Mclean's (2001) findings, which showed that there is a relationship between students' conceptions of learning and their academic achievement.

Furthermore, it is consistent with the findings of Purdie and Hattie (2002), who argued that the higher the level of students' conceptions of learning is in the hierarchy, the better their learning. Moreover, the study findings are congruent with Boulton-Lewis et al. (2000), Entwistle and Peterson (2004), and Allan (2003).

The significant role of learning as a process not bound by time or place and learning as the development of social competence in academic achievement prediction may be attributed to the students selecting better methods for learning. In this regard, Zhu, Valcke, and Schellens (2006) concluded that learning as a process not bound by time or place and learning as the devel- 
opment of social competence have a positive and significant relationship with deep and strategic methods but a negative and significant relationship with surface methods. To confirm these findings, Ellis, Goodyear, Calvo, and Prosser (2008) concluded that students who have deeper conceptions of learning score considerably higher on tests in their final year of study than students who have only surface conception of learning.

Consistent with the mentioned findings, different studies have concluded that students who have a higher level of conceptions of learning select better methods for learning and have higher academic achievement (Ellis et al., 2008; Cano \& CardelleElawar, 2004; Dart et al., 2000; Norton \& Crowley, 1995). Here, it is inferred that high academic achievement by students who choose learning as a process not bound by time or place and learning as the development of social competence can may be explained by their selection of deeper and better methods of learning. Therefore, we can infer that these conceptions of learning make learners show more flexibility in their thinking, as they process the information more actively and learn conceptually. These research findings suggest that, in order to increase students' academic achievement, educational content must be practical and used daily. If educational content is presented in a way that continuously involves students in real and natural situations, guiding them to independency and self-efficacy, then their conceptions of learning will be deeper and higher. Therefore, educators must offer opportunities for students to engage with society and the realities outside of school and to prepare successfully for social life. This means that if education and learning help students learn how to live in the real world, develop healthy relational skills with their peers and adults, and become active citizens in both school and society through meaningful experiences in the society, working and engaging in appropriate activities, and receiving continuous support and feedback from the environment, then the students' conceptions of learning will improve. In fact, if the student's educational schedules emphasize skill development in real life environments, we can predict that the students will have better academic achievement.

The second research aim is to examine the relationship between the number of students' conceptions of learning and their academic achievement. As shown in Table 4, there is a significant difference between students' academic achievement mean on the basis of the number of their conceptions of learning, such that the mean academic achievement of participants who have five or six conceptions of learning is significantly higher than that of those who do not have any conceptions of learning.

This is consistent with Purdie and Hattie's (2002) findings showing that the more conceptions of learning students have, the higher their academic achievement is. The findings of this study are also congruent with Purdie and Hattie (1999). Purdie and Hattie (2002) demonstrated that there is a strong relationship between the number of students' conceptions of learning and their academic achievement. Based on the findings of this study, it can be concluded that students who have higher academic achievement have multiple conceptions of learning rather than just one. In fact, students who have multiple conceptions of learning select different methods for learning. They integrate qualitative and quantitative approaches to learning and use various methods, paying attention to learning conditions and subject difficulty level (Lee, 1998). Lin and Tsai (2008) believe that students who have multiple conceptions of learning use a higher level of cognitive and metacognitive strategies and thinking skills, such as self-monitoring, and select different problem-solving strategies that are effective in their academic achievement. Thus, it can be inferred that students who havemultiple conceptions of learning use a combination of various learning methods to achieve academic success. In light of this research finding, we should encourage students to understand learning as a process of personal change, learning as a process not bound by time or place, and learning as the development of social competence. Further, we must help students to be responsible for their own learning and to learn more strategically.

Moreover, we must foster an environment that encourages students to have an interior motivation for learning. Additionally, to convey deeper conceptions of learning, we should formulate clear learning goals and purposes and relate educational materials directly to students' previous knowledge as well as to the learning goals. In addition, it is suggested to hold discussion groups on both learning contents and learning processes. Student learning should emphasize different approaches to problems and topics, and assessment should focus on the students' conceptual understanding of the material. Finally, it is suggested employ practical strategies to change students' conceptions of learning from surface conceptions to deep ones. Occupational education should be emphasized, class topics should be clearly related to real environments, instruction must be based on the society, career instruction must be combined with the teaching of life skills, and finally, education must be presented with an emphasis on adult outcomes.

\section{REFERENCES}

Allan, B. (2003). Approaches to learning and academic achievement of Filipino students. The Journal of Genetic Psychology, 164, 101-114. doi: $10.1080 / 00221320309597506$

Boulton-Lewis, G. M., Marton, F., Lewis, D. C., \& Wilss, L. A. (2000). Learning in formal and informal contexts: Conceptions and strategies of Aboriginal and Torres Strait Islander university students. Learning and Instruction, 10, 393-444. doi:10.1016/S0959-4752(00)00005-0

Cano, F., \& Cardelle-Elawar, M. (2004). An integrated analysis of secondary school students' conceptions and beliefs about learning. European Journal of Psychology of Education, 19, 167-187. doi:10.1007/BF03173230

Dart, B. C., Burnett, P. C., Purdie, N., Boulton-Lewis, G., Campbell, J., \& Smith, D. (2000). Students' conceptions of learning, the classroom environment, and approaches to learning. Journal of Educational Research, 93, 262-270. doi:10.1080/00220670009598715

Ellis, R. A., Goodyear, P., Calvo, R. A., \& Prosser, M. (2008). Engineering students' conceptions of and approaches to learning through discussions in face-to-face and online contexts. Learning and Instruction, 18, 267-282. doi:10.1016/j.learninstruc.2007.06.001

Entwistle, N. J., \& Peterson, E. R. (2004). Conceptions of learning and knowledge in higher education: Relationships with study behaviour and influences of learning environments. International Journal of Educational Research, 41, 407-428. doi:10.1016/j.ijer.2005.08.009

Hong, Y. Y., \& Salili, F. (2000). Challenges ahead for researchon Chinese students' learning motivation in the new millennium. Journal of Psychology in Chinese Societies, 1, 1-12.

Klatter, E. B., Lodewijks, H. G. L. C., \& Aarnouste, C. A. J. (2001). Learning conceptions of young students in the final year of primary education. Learning and Instruction, 11, 485-516. doi: 10.1016/S0959-4752(01)00002-0

Lai, P. Y., \& Chan, K. W. (2005). A structural model of conceptions of learning, achievement motivation and learning strategies of Hong Kong teacher education students. Australian Association of Research in Education Parramatta Conference, Sydney, 28 November-2 December.

Lee, Y. (1998). Assessing and fostering senior secondary school stu- 
dents' conceptions and understanding of learning through authentic assessment. Master's Thesis, Hong Kong: University of Hong Kong.

Lin, M., \& Tsai, C. (2008). Conceptions of learning management among undergraduate students in Taiwan. Management Learning, 39, 561-578. doi:10.1177/1350507608096041

Marton, F., Dall'Alba, G., \& Beaty, E. (1993). Conceptions of learning. International Journal of Educational Research, 19, 227-300.

McLean, M. (2001). Can we relate conceptions of learning to student academic achievement? Teaching in Higher Education, 6, 399-413. doi:10.1080/13562510120061241

Norton, L. S., \& Crowley, C. M. (1995). Can students be helped to learn how to learn? An evaluation of an approaches to Learning programme for first year degree students. Higher Education, 29, 307328. doi:10.1007/BF01384496

Peterson, E. R., Brown, G. T. L., \& Irving, S. E. (2010). Secondary school students' conceptions of learning and their relationship to achievement. Learning and Individual Differences, 20, 167-176. doi:10.1016/j.lindif.2009.12.004

Purdie, N., \& Hattie, J. (1999). The relationship between study skills and learning outcomes: A meta-analysis. Australian Journal of Education, 43, 72-86.

Purdie, N., \& Hattie, J. (2002). Assessing students' conceptions of learning. Australian Journal of Educational and Developmental Psychology, 2, 17-32.

Purdie, N., Hattie, J., \& Douglas, G. (1996). Student conceptions of learning and their use of self-regulated learning strategies: A crosscultural comparison. Journal of Educational Psychology, 88, 87-100. doi:10.1037/0022-0663.88.1.87

Seif, A. (2008). Educational psychology. Tehran: Doran.

Zhu, C., Valcke, M., \& Schellens, T. (2006). A cross-cultural study of Chinese and Flemish university students: Do they differ in learning conceptions and approaches to learning? Ghent: Ghent University. 